\title{
The European Identity in the Classical Psyche of Greece: Between Values and Strategic Vision
}

\section{A Identidade Europeia na Psique Clássica da Grécia: Entre Valores e Visão Estratégica}

\author{
Evanthia Balla, \\ University of Évora, Portugal
}

\begin{abstract}
Resumo-O objetivo deste artigo é fornecer uma referência adequada tanto aos atuais especialistas no domínio das Relações Internacionais e Estudos Europeus como aos que se dedicam ao tema pela primeira vez. Enquanto a Grécia celebra 200 anos desde o lançamento da Luta Pela Independência Grega (1821-2021) e do 40.ž aniversário da adesão da Grécia às Comunidades Europeias (hoje União Europeia), este artigo visa uma análise reflexiva dos principais temas do desenvolvimento que moldaram a identidade estratégica da Grécia, desde 1821 até à recente crise financeira. $O$ presente estudo avalia a literatura existente sobre o tema e traça agendas para investigação futura, a fim de construir sensibilização sobre a importância de aprofundar os nossos conhecimentos sobre as identidades estratégicas distintas dos diferentes Estados-Membros da UE. Compreende dimensões conceptuais e empíricas para aprofundar a apreciação dos desenvolvimentos na política, instituições e políticas gregas e ligá-los a um contexto histórico internacional mais vasto. O principal argumento é que a Grécia tem feito escolhas estratégicas especificas, respondendo ao ambiente político internacional ao longo do tempo, em que a ligação entre o seu legado clássico, a Europa e o Ocidente esteve sempre presente.
\end{abstract}

Palavras-Chave-Grécia; Europa; Estratégia; Identidade.

\begin{abstract}
The purpose of this article is to provide a reference appropriate to both current specialists in the field of International and European Studies and those delving into the subject for the first time. As Greece celebrates 200 years since the launch of the Greek Struggle for Independence (1821-2021) and the 40th anniversary of Greece's accession to the European Communities (now European Union), this article aims at a reflective analysis across the key themes that have shaped Greeces strategic identity, from 1821 until the recent financial crisis. The current study reviews the existing literature on the subject and outlines an agenda for future research to build up knowledge and awareness on the importance of deepening our knowledge on the distinct strategic identities of the various EU Member-States. It comprises conceptual and empirical dimensions to deepen the appreciation on Greek politics, institutions, and policies and to connect them to a wider, international historical context. The main argument is that Greece has made strategic choices responding to the international political environment over time, in which the liaison between its classical legacy, Europe and the West have always been present.
\end{abstract}

Keywords-Greece; Europe; Strategy; Identity.

Submitted-05-01-2021. Accepted-07-05-2021. 


\section{Introdução}

A celebração dos 200 anos do início da A Guerra da Independência da Grécia, ocorrida em 1821, e a comemoração dos 40 anos da adesão do país à União Europeia em 1981, é hoje simultaneamente uma ocasião para reconhecer o processo evolutivo que traçou a identidade da Grécia Moderna, e nos obriga a refletir sobre a posição atual do país e sobre o seu futuro.

\section{Porquê a Grécia?}

A Grécia é considerada o berço da civilização ocidental e é fonte de algumas das maiores realizações intelectuais, científicas e artísticas da humanidade. Neste contexto, a Grécia carrega uma enorme herança simbólica no mundo, embora desproporcional face ao seu atual poder e influência. Hoje em dia, a Grécia é vista como um país que sofre de baixos níveis de desenvolvimento económico e estrutural, e problemas sociais significativos. A recente crise financeira colocou a Grécia no centro das atenções, tendo recebido uma publicidade negativa pelos média internacionais, que provocaram uma onda de contestações dentro do próprio Estado Helénico ${ }^{1}$, sendo a mais notória a do antigo Presidente da República, Károulous Papúlias, que em 2012 declarou [...] "We [the greeks] always had the pride to defend not just our own freedom, not just our own country, but the freedom of all of Europe. ${ }^{\prime 2}$

Nos últimos anos, uma produção académica considerável procurou identificar os quadros conceptuais e empíricos através dos quais devemos compreender a Grécia Moderna (Kitromilides 2013; Triandafyllidou, Grobas e Kouki (eds) 2013; Kalyvas 2015; Arabatzis, Steiris e Mitralexis

- Evanthia Balla, Assistant Professor at the University of Evora and Collaborative Member of the Research Center in Political Science (CICP).

E-mail: eballa@uevora.pt

DOI:http://dx.doi.org/110.21814/perspectivas.3371

1. Os gregos não utilizam o termo Grécia, mas o antigo nome Hellas.

2. "Irritation in Athens. 'I Don't Accept Insults to My Country by Mr. Schäuble". Speigel Internacional. Disponível em https://www.spiegel.de/international/europe/irritation-inathens-i-don-t-accept-insults-to-my-country-by-mr-schaeublea-815651.html 16.02.2012 último acesso: 25 de março 2021. Sobre a crise grega e os média, ver Tzogopoulos, George. 2013. The Greek Crisis in the Media: Stereotyping in the International Press. Routledge. 1st edition. (eds) 2016; Beaton 2019; Featherstone e Sotiropoulos (eds) 2020; Kitromilides 2020; Kitromilides e Tsoukalas (eds) 2021).

$\mathrm{Na}$ realidade, quando procuramos definir a identidade da Grécia Moderna, o debate desenvolve-se em torno de duas questões principais e distintas, mas ao mesmo tempo, interligadas em termos de estratégia e valores:

1. Qual é a verdadeira relação entre a Grécia Moderna e o seu legado histórico por parte da Grécia Clássica? 2. A que parte do mundo é que a Grécia pertence hoje, em termos de estratégia e ideais, ao Ocidente ou ao Oriente? ${ }^{3}$ E porquê?

Quanto à ligação da Grécia Moderna à civilização clássica, esta tem gerado diversos sentimentos, contribuindo para uma postura defensiva dos próprios gregos, particularmente quando a ligação entre os dois é contestada, como relata Kalyvas $(2015,7)$. O livro "History of the Morea Peninsula during the Middle Ages"do escritor austríaco alemão Jakob Phillip Fallmerayer, defendia que os habitantes da Grécia Moderna não eram os herdeiros da Grécia Clássica, mas eram descendentes das populações eslavas, que se instalaram na região durante os séculos sexto e sétimo dC. Afirmações essas que receberam grandes críticas.

Exemplo destas críticas foi o artigo intitulado "Genetics of the peloponnesean populations and the theory of extinction of the medieval peloponnesean Greeks"(Stamatoyannopoulos, Bose, Teodosiadis et al. 2017) que examina a ancestralidade genética das populações do Peloponeso e prova uma relação insignificante entre os gregos do Peloponeso e os eslavos, rejeitando assim as afirmações de Fallmerayer, que por este motivo seriam inválidas. Mais uma pesquisa foi publicada no mesmo ano, intitulada "Genetic origins of the Minoans and Mycenaeans"(Lazaridis, Mittnik, Patterson et al. 2017). Os resultados dessa pesquisa sustentam que os gregos modernos se assemelham aos micénicos, mas com alguma diluição adicional da

3. O Ocidente é um conceito bastante instável. Contudo, para os objetivos do presente trabalho, o termo Ocidente refere-se à Europa Ocidental, e com o início da Guerra Fria, ao chamado Mundo Ocidental e à aliança transatlântica (Mitralexis, 2017). O termo Oriente refere-se ao Oriente como enfase nas relações do país com a Turquia e a Rússia. Sobre as diferentes versões do Ocidente, consulte Lewis Martin W. e Wigen, Kären. 1997. The Myth of Continents: A Critique of Metageography. Berkeley: University of California Press. 
ancestralidade neolítica primitiva. Apoia ainda a ideia de continuidade, mas não de isolamento na história das populações do Mar Egeu, antes e depois do tempo das suas primeiras civilizações.

Igualmente, posturas e sentimentos de orgulho refletem-se em momentos diversos por afirmações de personalidades célebres das Letras e das Artes.

I belong to a small country. A rocky promontory in the Mediterranean, it has nothing to distinguish it but the efforts of its people, the sea, and the light of the sun. It is a small country, but its tradition is immense and has been handed down through the centuries without interruption. (Giórgos Seféris, 1963) ${ }^{4}$

Relativamente ao debate sobre a segunda questão, pensadores do mundo político e académico têm argumentado que a Grécia não pertence ao Ocidente. Kalyvas apresenta bem este debate através das suas referências ao ex-presidente francês Vallery Giscard dt Estaing que durante a recente crise financeira de 2009 captou grande parte da perceção predominante, quando observou que "A Grécia é basicamente um país oriental". Kalyvas ainda se refere a um observador, que já no início do século passado, em 1911, descrevia os gregos como "europeus em termos geográficos e de raça (raciais), embora não ocidentais. Orientais com um orientalismo que não é asiático; uma ponte entre o Ocidente e o Oriente." (Kalyvas 2015, 5). Do mesmo modo, com o fim da Guerra Fria, Samuel Huntington, na sua famosa tese do choque de civilizações, publicada pela primeira vez em 1993, excluía a Grécia do Ocidente com base na sua religião, cultura, diferente postura face à Sérvia e ligação especial com a Rússia. Contudo, a história da Grécia revela uma estreita ligação com o Ocidente, em termos políticos, económicos e culturais. Nas palavras de Konstantinos Karamanlís "Greece, be it traditionally or because of interest, belongs to the Western world." 5

4. Discurso de Giórgos Seferis na cerimónia de entrega do Prémio Nobel da Literatura em 1963 disponível em https:// www.nobelprize.org/prizes/literature/1963/seferis/speech/ último acesso: 25 de março 2021

5. Discurso do primeiro-ministro grego da época, Konstantinos Karamanlís, no Parlamento Helénico, em 1976. Disponível em https://www.youtube.com/watch?v=wi75X_IGWoo último acesso: 25 de março 2021
Na realidade, as identidades não são elementos estáticos. Tanto a localização geográfica como a continuidade linguística implicam a existência de uma estreita ligação entre a Grécia Moderna e a Grécia Antiga, com as eras: romana, bizantina e otomana a fornecerem as principais rotas históricas desta viagem. Todavia, a ascensão da Grécia Moderna não foi um processo propriamente linear. A variedade de sistemas políticos, as estruturas sociais e culturais, que traçaram a história grega, revelam um processo complexo e heterogéneo.

Neste contexto, o presente estudo visa decifrar essa complexidade da identidade grega moderna, utilizando ferramentas conceptuais e empíricas. Observa os acontecimentos históricos e políticoinstitucionais, desde a criação do estado grego moderno até à crise financeira de 2009, através de um estudo qualitativo de análise documental. Examina a idiossincrasia política do país, através de ideologias e estratégias que traçaram o seu caminho histórico. Argumenta-se que a identidade grega se desenvolveu ao longo do tempo, influenciada pelo contexto político particular de cada época; e reflete-se em escolhas estratégicas concretas do país, desde a sua conceção moderna até hoje.

\section{Revolução e construção ideológica da identidade grega}

A luta armada dos gregos para a Independência do Império Otomano começou há dois séculos, em 1821. A Guerra foi marcada pela influência da Revolução Americana e Francesa (1775 e 1789, respetivamente), e pelos princípios ideológicos e culturais do Iluminismo e do Romantismo, e esteve sempre condicionada pelos interesses estratégicos das grandes potências da época, tornando-se assim num fenómeno pan-europeu (Blinkhorn e Veremis 1990; Kitromilides 2013, 2021; Tsoukalas 2021).

$\mathrm{Na}$ realidade, a revolução foi baseada num nacionalismo gerado por um processo intelectual conhecido como Iluminismo Grego, produto da interação de atores sociais distintos, mas interligados, tais como um grupo de elites metropolitanas cristãs, que exercia cargos de prestígio na administração otomana, conhecidos como Fanariótes 
(tais como Aléxandros Mavrokordátos e Aléxandros Ypsilantis). Esta quase-aristocracia, apesar de estar bem integrada no Império Otomano, promovia o cristianismo e a civilização helénica e a prevalência gradual dos mesmos. Um outro grupo de comerciantes e intelectuais de língua grega, que vivia em todo o Império Otomano, e em vários países europeus, também contribuiu para esse processo intelectual da causa grega. Algumas das forças catalisadoras mais conhecidas dessa conjuntura foram Rigas Feréos, e Adamántios Koraís.

Rigas Feréos (ou Rigas Velenestinlís) viajou entre as províncias danúbias, Habsburgo e Império Otomano, publicando e propagando a sua visão para a construção de uma confederação republicana de todos os grupos étnicos com base nos ideais da revolução francesa. No fundo, Feréos idealizava o ressurgimento do império bizantino, mas substituindo a autocracia de Bizâncio por instituições republicanas do modelo francês. (Clogg 1992, 29; kalyvas 2015, 18 e 21; Beaton 2019, 53).

Em 1797, Feréos escrevia no seu famoso poema de guerra "Thoúrios"

Better one hour of free life, Than forty years of slavery and prison! (citado por Clogg, 31)

resumindo assim a determinação revolucionária grega.

Adamántios Koraís, por sua vez, argumentou a favor da criação de um estado grego moderno baseado no modelo e normas da Europa Ocidental e numa identidade nacional com ênfase particular na herança clássica da Grécia Moderna (Droulia 1997; Kitromilides 2010; Beaton 2019). Ideias essas que contrariavam as vozes tradicionalistas que enfatizavam a importância de Bizâncio e da tradição oriental e promoviam um modelo de organização política eslava. Em 6 de janeiro de 1803, na sua obra "Dissertation on the present state of civilization in Greece", Korais descreve explicitamente o despertar da consciência grega para a responsabilidade de tentar fazer jus aos seus ancestrais (Droulia 1997; Beaton 2019, 60$61)$.

A Igreja Ortodoxa Cristã, e mais precisamente o Patriarcado Ecuménico de Constantinopla que chefiava a igreja, foi também instrumental para a consolidação da identidade nacional da Grécia Moderna, sendo uma componente essencial do nacionalismo grego heleno-cristão. Historicamente falando, a Igreja Ortodoxa participou na construção da nação grega, agindo como um guia cultural, social e espiritual durante o domínio otomano e a Guerra da Independência; através da sua língua litúrgica e administrativa e das suas instituições educacionais. No entanto, importa referir que a Igreja Ortodoxa Cristã promoveu, mas nunca endossou o iluminismo grego, ideologia que considerava hostil à sua própria autoridade religiosa (Kalyvas 2015, 19). Essa autoridade religiosa esteve sempre presente na identidade grega; e reflete-se ainda hoje na estreita ligação prémoderna entre Estado e Igreja (Kitromilides 2020; Frary 2021).

Com a viragem do século XIX, as referências ideológicas transitaram do Iluminismo para o Romantismo. Os princípios do Romantismo promoveram o crescimento e a expansão do Filelenismo (movimento de apoio à luta pela independência da Grécia face ao Império Otomano). De facto, os gregos também lutavam contra o domínio e a favor dos valores europeus. Evidência disso tinha sido a primeira constituição adotada em 1822, uma constituição extremamente liberal para a época (Kalyvas 2015, 30).

Os ideais da Grécia Clássica já estavam enraizados na identidade europeia, e agora os gregos procuravam conquistar estes mesmos ideais de novo. Tsoukalas argumenta que na realidade não só a Grécia Antiga era considerada a maior conquista da história humana, mas os europeus também tendem a lisonjear-se, descobrindo os seus próprios antepassados culturais idealizados na Grécia Antiga. Com efeito, o expansionismo e o domínio europeus basearam-se na construção e apropriação do mito racista de uma civilização proto-europeia superior e indígena, que era claramente distinguível, desde as suas origens, do Oriente inferior e bárbaro (Tsoukalas 2002, 75).

Thus, 'Hellenolatry' served as a powerful ideological weapon for expanding European power. (Tsoukalas 1999, 8)

O poeta Lord Byron foi um dos mais importantes filelenos ingleses, e uma das figuras mais 
influentes do Romantismo.

Byron escrevia:

I dreamd that Greece might still be free; For standing on the Persians grave, I could not deem myself a slave. ${ }^{6}$

Em paralelo com o poderoso movimento de filelenismo, que ligava o legado grego clássico à Europa e aos seus ideais e vice-versa, e era defensor de um governo central e uma constituição ao estilo europeu, uma outra corrente tradicionalista começava a surgir no plano político, que considerava a Grécia ancorada no Oriente, em termos de identidade e interesses, em contraponto ao Ocidente, visto como uma "maldição"para os gregos. Esta visão foi partilhada na época por certos círculos eclesiásticos e também militares para os quais o Ocidente era um anátema (Koliopoulos e Veremis 2010, 22).

Quanto à estrutura e planeamento da revolução, uma organização secreta conhecida como Filikí Eteria (Sociedade dos Amigos) foi fundada em Odessa, na comunidade da diáspora no sul da Rússia, em 1814, com o objetivo primordial de apoiar e propagar o ideal da revolução e organizar a revolta armada. Tratava-se de um grupo político clandestino, que na sua maioria era composto por comerciantes, nobres, militares e clérigos. Inspirado na maçonaria, funcionou com base em rituais e regras estritas. O verdadeiro valor da Sociedade de Amigos, baseou-se na criação de uma rede significativa de apoiantes da causa grega, um veículo de conspiração dentro e fora do Império Otomano (Kalyvas 2015, 24; Beaton 2019, 69, 78, 79; Clogg 1992, 32).

Em 6 de março de 1821, Aléxandros Ypsilantis, líder da organização e oficial superior do exército russo, num ato de grande simbolismo atravessou de barco o rio Prut, que separava os dois impérios russo e otomano, e entrou na Moldávia, território otomano (Beaton 2019, 78). Releve-se que a organização tinha criado intencionalmente o mito do apoio russo, apresentando assim a revolução grega como uma luta cristã contra um opressor muçulmano. Contudo, o envolvimento russo

6. Lord Byron. 1819. The Isles of Greece. Disponível em https: //englishverse.com/poems/the_isles_of_greece último acesso: 25 de março 2021 não ocorreu neste ato, como era esperado. Evidentemente, a Rússia, enquanto fiel membro do Congresso de Viena, que visava a restauração da ordem absolutista na Europa, não poderia apoiar uma revolução na sua periferia. (Kalyvas 2015, 25). No entanto, os laços grego-russos observam-se ao longo de todo o processo da criação da entidade grega moderna, tanto por via da relação cultural e religiosa estreita entre as duas nações, como também através do interesse estratégico russo nos Balcãs otomanos e as ligações económicas importantes entre os dois países. É de notar o crescimento de um empreendedorismo económico dinâmico no mar negro na época. Na segunda década do século XIX, Odessa era o porto em crescimento mais rápido do mundo, onde uma grande comunidade grega de comerciantes se instalou e instituiu escolas, bancos e hospitais (Frary 2015, 25).

O dia 25 de março foi definido como data oficial da revolução grega pela Sociedade dos Amigos, dando assim uma ressonância simbólica ao acontecimento, sendo o dia de celebração religiosa cristã da anunciação de Nossa Senhora.

Para os insurgentes, a Europa era sinónimo de liberdade, prosperidade, dignidade e estado de direito; valores esses que o novo estado procurava garantir para ele próprio. Neste contexto, Ioánnis Kapodístrias foi escolhido como o líder mais adequado para preparar um estado moderno e implementar um programa de organização administrativa, importando políticas e instituições ao estilo europeu. Kapodístrias adquiriu a sua experiência política na Rússia, como ministro dos negócios estrangeiros do czar Alexandre Primeiro e na Suíça (Beaton 2019, p. 105). Kapodístrias (1827-31) conseguiu suprimir a pirataria e estabelecer um sistema de educação. No entanto, o seu autoritarismo, as clivagens ideológicas internas entre os modernistas e os tradicionalistas, e uma oposição feroz da parte dos caudilhos, despertaram grandes contestações e acabou por ser assassinado. (Koliopoulos e Veremis 2010, 26; Hatzis 2019, 3-5).

Quanto ao cenário político internacional da época, como já referimos, esse não era favorável a movimentos revolucionários, sendo estes considerados uma ameaça para o status quo absolutista da época. As grandes potências, todavia, acaba- 
ram por se evolver na guerra, iniciando assim uma longa tradição de intromissão nos assuntos internos do país. O envolvimento das potências europeias deveu-se a dois fatores/interesses estratégicos fundamentais (Arabatzis, Steiris e Mitralexis (eds) 2016; Mitralexis 2017). Em primeiro lugar, a revolução grega poderia alterar o equilíbrio de poder entre as duas grandes potências em expansão da época, a Grã-Bretanha e a Rússia. Os britânicos procuraram contrariar a ascensão da influência russa no Mediterrâneo Oriental e viram um estado grego recém-formado como um tampão às ambições da Rússia. Os russos, por outro lado, viram o surgimento de um novo Estado ortodoxo cristão como um potencial aliado. Neste contexto, a batalha determinante para o resultado e vitória da Revolução Grega foi travada na Baía de Navarino em 20 de outubro de 1827 , com o apoio britânico, francês e russo (Holland 2021, 281-296). A Grécia foi declarada um Estado monárquico independente sob a proteção dessas mesmas potências, com o protocolo de Londres, que foi assinado em 3 de fevereiro de 1830. Quanto às intenções gregas, importa referir que os revolucionários tinham solicitado a intervenção dos britânicos e não dos russos (Kalyvas 2015, 31; Beaton 2019, 97).

No cenário político surgem assim três partidos, o russo, o francês e o britânico, procurando apoiar os interesses geostratégicos dos respetivos países na região. A escolha do Príncipe Oto da Baviera como primeiro rei da Grécia livre também foi reveladora de uma contínua intromissão estrangeira nos assuntos internos do país, até hoje presente na psique grega. Essa realidade encorajou a disseminação da crença de que os fracassos da Grécia eram causados pela influência externa, criando uma predisposição natural do povo grego para resistir a persistente "invasão"(Kalyvas 2015, 8).

Efetivamente, o reconhecimento da independência da Grécia em 1830 foi a primeira tentativa europeia a favor de um movimento de libertação nacional. E isso aconteceu, parcialmente, graças ao significado universal da herança helénica clássica. Para os próprios gregos, além da liberdade, garantir um lugar de direito na família das nações europeias era também um interesse vital (Koliopoulos e Veremis 2010, 23). Do mesmo modo, o processo de construção da identidade grega moderna surge entre dois movimentos ideológicos e políticos antagónicos, ainda hoje presentes na sociedade helénica, um dualismo cultural como o descreveria em 1993 Diamandouros (Diamandouros 1993, 4). Trata-se da cultura oriental, tradicionalista, pré-moderna e suspeita/insegura para com o Ocidente, underdog culture, e a cultura do iluminismo, essencialmente laica, e pró-ocidental (Triandafyllidou, Gropas e Kouki 2013, 3).

\section{A Grécia livre e a evolução da iden- tidade grega}

A Grécia livre esteve sempre condicionada por um conjunto de fatores tanto de natureza interna como externa: tais como as divisões dentro do próprio sistema político e o facto de viver períodos prolongados de instabilidade e guerra.

A independência veio colocar na agenda política nacional duas questões principais, a unidade territorial e a governança política. Neste contexto, a identidade grega ficou marcada, por um lado, pela ambição de reunir todos os gregos, nascidos dentro e fora das fronteiras do reino (autóctones e heteróctones respetivamente) num único Estadonação e, por outro lado, pela transição de uma nação num novo Estado-nação, duas das constantes da política e da diplomacia grega do século XIX.

As aspirações irredentistas da época são conhecidas como a "Grande Ideia"(em grego: Megáli Idéa); que visavam a criação de uma potência regional, que combinaria o alcance simbólico da Grécia antiga com o legado ortodoxo de Bizâncio e teria a sua capital mais uma vez estabelecida em Constantinopla (Skopetea 1988; Veremis 2020, Hatzis 2019).

Entre 1864 e 1881, o território grego foi alargado pacificamente. A Grã-Bretanha cedeu as ilhas Jónicas à Grécia em 1864, como presente por não estar do lado da Rússia na Guerra RussoTurca de 1877-1878. Mais tarde, em 1881, foi anexada a Tessália e parte de Épiro. No entanto, estes pequenos ganhos territoriais não conseguiram satisfazer a Megáli Idéa. Adicionalmente, a questão de Creta pressionava enormemente os sucessivos governos gregos e acendia fortes sentimentos nacionalistas; pois, os cretenses revoltaram-se quase ininterruptamente contra as autoridades otomanas durante o século XIX. 
Na sequência da Guerra Greco-Turca de 1897, foram efetuados pequenos ajustamentos territoriais à linha fronteiriça greco-otomana a favor dos otomanos. E Creta torna-se um estado autónomo apenas em 1898, após pressões ao sultão vindas das grandes potências, Grã-Bretanha, França, Itália e Rússia (Koliopoulos e Veremis 2010, 56).

Durante o período da monarquia absoluta do rei Oto, a idiossincrasia liberal grega foi muitas vezes desafiada, levando à revolta de 3 de setembro de 1843; revolta essa que abriu o caminho para a adoção da primeira constituição pós-independência. Uma monarquia constitucional foi assim estabelecida em 1844, através do primeiro sufrágio masculino universal. A guerra da Crimeia entre o Império Russo e o Império Otomano (1853-1856), contudo, veio provocar novamente um descontentamento generalizado contra o rei Oto, por não ter apoiado a estratégia franco-britânica, prejudicando assim os interesses estratégicos do país (Kalyvas 2015, 46). Oto foi conduzido a abdicar o trono em 1862. O seu sucessor foi um príncipe dinamarquês da Casa de Glücksburg, que se tornou o rei Jorge I e reinou durante meio século (1863-1913). Era um anglófilo disposto a aceitar uma constituição democrática, constituição essa que foi adotada em 1864, tornando a Grécia numa das primeiras democracias parlamentares do mundo.

No último quarto do século XIX, o regime político do país foi marcado por um sistema de dois partidos em que o poder alternava entre dois homens: Kharílaos Trikoúpis e Theódoros Dhiliyiánnis. Trikoúpis representava a tendência modernizadora e de ocidentalização do país, e Dhiliyiánnis era um chefe político tradicional, sem nenhum programa real que não fosse derrubar as reformas do seu arquirrival (Koliopoulos e Veremis, 2010). Entretanto, os esforços militares agravavam os problemas económicos, que culminaram na falência nacional em 1893.

Desde a sua independência, o Estado grego procurou alcançar o sonho da Grande Ideia e uma modernização política, económica e social semelhante ao modelo europeu. Neste esforço, porém, o constante conflito interno entre os apoiantes e os opositores da modernização (Diamandouros 1993, 1994) e a instabilidade externa constituíram obstáculos que atrasaram significativamente este processo.

\section{Século XX - A consolidação de uma identidade entre crises e triunfos}

No século XX, a identidade grega continua a moldar-se em paralelo com a necessidade de segurança e afirmação na região, aproveitando referências ao seu glorioso passado e a aliança inegável com as grandes potências. Nikos Svoronos argumentou que "o significado mais profundo da história da Grécia moderna pode ser resumido ao doloroso esforço de um povo antigo para se transformar numa nação moderna, adquirir uma consciência do seu caráter especial e ganhar a sua posição de direito no mundo moderno." (citado por Kalyvas 2015, 8)

O início do século XX foi marcado pelo jogo de poder entre potências regionais e europeias; jogo esse que conduziu às guerras dos Balcãs e mais tarde às duas grandes Guerras. A Grécia participou ativamente nestes conflitos, conseguindo vitórias que lhe permitiram alargar os seus territórios e aproveitar um apoio externo crucial para o seu desenvolvimento, mas sofrendo também perdas dramáticas que ficaram para sempre gravadas na sua memória histórica.

A Grécia participou na Guerra dos Balcãs (1912-13), fazendo parte das alianças vencedoras. Como resultado, aumentou o seu território, com a Macedónia Grega e a ilha de Creta. Do mesmo modo, a Grécia entrou na Primeira Guerra Mundial em 1917, ao lado dos Aliados (Triple Entente: Reino Unido, França e Rússia). Após a vitória dos Aliados, a Grécia ficou responsável pela administração de Smyrna (e da sua periferia), na Ásia Menor, habitada por uma população mista cristã e muçulmana e por uma considerável população grega. O Tratado de Sèvres, em 1920, oficializou a presença grega na Ásia Menor e formalizou os ganhos territoriais gregos: da Trácia (no nordeste da Grécia, entre os mares Negro e Egeu) e das ilhas do mar Egeu (Kalyvas 2015, 2020).

Contudo, a chegada das tropas gregas à costa da Ásia Menor provocou uma onda de violência intercomunitária, que levou ao surgimento do nacionalismo turco. Sob a liderança de Mustafa Kemal Atatürk, um movimento turco de resistência emergiu contra os remanescentes do Império 
Otomano e principalmente contra o exército grego e a população cristã da Anatólia. A Grécia foi forçada a devolver todos os territórios conquistados durante os confrontos. Os conflitos ficaram conhecidos como as Guerras da Ásia Menor de 1921, uma catástrofe que provocou uma crise de refugiados sem precedentes e marcou o fim das ambições irredentistas da Grécia (Hatzis 2019, 8).

A Grécia não tinha intenção de entrar na Segunda Guerra Mundial. A estratégia do primeiroministro da Grécia na época, Ioánis Metaxas, era de a manter neutra durante o conflito. No entanto, quando as tropas italianas de Mussolini exigiram a entrega incondicional do país, Metaxas categoricamente recusou, com um famoso Ochi (tradução: não) "Donc, Monsieur, c'est la guerre"(Beaton 2019, 267), dito no dia 28 de outubro de 1940 (dia nacional na Grécia). Como resultado, a Itália tentou invadir a Grécia, porém, o exército grego travou a invasão e rapidamente forçou as forças italianas a refugiarem-se na Albânia. Situação essa que obrigou Hitler a lançar um bombardeamento nos Balcãs em abril de 1941. As defesas gregas colapsaram e os alemães entraram em Atenas, logo depois. A ocupação que se seguiu foi extremamente violenta e destrutiva. Todavia, os gregos mantiveram a resistência contra as forças nazis até ao final da Guerra (Clogg 1992; Kalyvas 2015, 2020).

É pertinente salientar que neste período a relação entre o Oriente e o Ocidente Europeu, em termos de estratégias, não era uma relação de clara divisão. Evidentemente, a aliança entre países, tais como o Reino Unido, os Estados Unidos da América (EUA) e a União Soviética, foi crucial para garantir a vitória dos aliados e a salvaguarda de interesses comuns durante as duas Grandes Guerras. Neste contexto, a Grécia fez escolhas estratégicas de forma a garantir os seus próprios interesses nacionais.

Com o fim da Segunda Guerra Mundial, a divisão entre dois pólos de poder globais e ideologias distintas da União Soviética e dos Estados Unidos da América veio marcar uma grande parte do Século XX. Paradoxalmente, essa divisão encontra a sua primeira afirmação num conflito interno num país do mediterrâneo oriental, a Grécia. A guerra civil grega (1946-1949) que se inicia com a criação do Exército Democrático da Grécia
(Democratic Army of Greece, DSE) pelo Partido Comunista Grego (KKE) e o lançamento de uma insurreição em larga escala contra o governo de Atenas, também assinalou o início da Guerra Fria. A guerra envolveu as forças armadas do governo monárquico grego, protegidas pelo Reino Unido e pelos EUA, contra o Partido Comunista da Grécia, apoiado pela Rússia. Com o grande apoio financeiro e político dos americanos, o governo manteve-se no poder e a Grécia juntou-se oficialmente ao Mundo Ocidental, the West of the Cold War Atlantic aliance (Mitralexis 2017). De referir que a Grécia foi o único dos países vizinhos nos Balcãs que fugiu ao comunismo, continuando a moldar a sua identidade com base em escolhas políticas concretas, afirmando interesses comuns em termos de estratégia e valores com o Ocidente.

Apoiada pelo governo americano através da Doutrina Truman e do Plano Marshall de 1947, a economia grega havia sido estabilizada já nos finais da década de 1950. A Grécia aderiu à NATO, uma das organizações-chave do Ocidente no domínio de segurança e defesa, em 1952. Da mesma forma, solicitou a abertura de negociações com a Comunidade Económica Europeia (CEE) em 1959, apenas um ano após a entrada em vigor do Tratado de Roma, e acabou por assinar em 1961 um acordo de associação muito abrangente e ambicioso, com os seis membros fundadores. Com este acordo, a Grécia tornou-se o primeiro membro associado da CEE (Tsoukalis 2020; Featherstone e Papadimitriou 2020).

O período entre 1961 e 1973 foi um período de crescimento económico notável do país, que alcançou uma taxa média de crescimento de 7,4\%, o que colocou a Grécia entre os principais países em desenvolvimento a nível global. Isso foi possível graças a uma combinação de estabilidade política; estabilização monetária (com base na indexação do dracma ao dólar, o que levou a uma maior confiança na moeda grega); estabilidade macroeconómica (baixa inflação e orçamentos do estado equilibrados ou quase); a abertura ao comércio internacional; o investimento maciço em infraestruturas (Kalyvas 2015, 2020).

Em termos de regimes políticos, o país experimentou três interrupções relativamente curtas dos seus governos democráticos: 1922-1929, 1936-1945 e 1967-1974. Durante o mesmo período, várias 
divisões ideológicas continuavam a abalar o país. O Cisma Nacional (em grego: dichasmós), que refletia o confronto entre o estadista grego liberal Elefthérios Venizelos e o monarca Konstantino, ia dividir o país durante décadas. Venizelos apoiava a participação da Grécia na Guerra ao lado da "Triple Entente"enquanto o rei, sendo próximo da Alemanha, defendia a neutralidade do país. O cisma entre campos distintos instrumentalizou a tradição e a modernização de formas diferentes, vacilando entre o Oriente e o Ocidente.

Foi sobretudo após a transição para a democracia, em 1974, com o fim da junta militar de sete anos e a abolição da monarquia, que uma série de mudanças significativas trouxeram o país para o caminho de uma verdadeira modernização (Triandafyllidou, Gropas e Kouki, 2013; Featherstone 2020).

O período pós 1974 é conhecido como "metapolítefsi"; foi um momento crítico que marcou e reafirmou as escolhas estratégicas do país para com as estruturas ocidentais. A candidatura à adesão a Comunidade Europeia foi submetida pelo governo da Nova Democracia (ND), liderado por Karamanlis já em junho de 1975. Os ideais da unidade e democracia europeias foram, mais uma vez, misturados com referência à história e à alta política (Tsoukalis 2020, 586). Karamanlis já tinha retirado as forças gregas da estrutura militar da NATO devido à incapacidade de organização para impedir a invasão de Chipre pela Turquia em 1974. Assim, a CE foi apresentada como uma espécie de substituto da NATO, ou seja, substituição da velha Pax Americana por um nova Pax Europaea (Karamouzi 2014; Tsoukalis 1981; 2020).

Na realidade, Karamanlís poderia contar com um forte apoio dos EUA para a participação da Grécia na construção europeia, pois o projeto europeu reforçava a aliança transatlântica construída em oposição a um inimigo comum, an alliance founded on opposition to a common threat, o poder soviético (Daalder 2000). O restabelecimento da democracia liberal na Grécia tornavase assim fundamental para este propósito. Karamanlis tratou o Atlântico e o Europeísmo como estratégias complementares, não antagónicas. Ao longo destes anos, a Grécia, juntamente com outros países do Sul da Europa, lutava desespera- damente para escapar às armadilhas do subdesenvolvimento. Logo, para o governo de Karamanlis a opção pela europeização era óbvia (Hatzivassiliou 2020).

A relação da Grécia com a Europa ganhou uma dimensão especial com a adesão plena do país às Comunidades Europeias em 1981. Contudo, a presença da Grécia nas Comunidades passou por várias fases: o período inicial foi marcado pelo clima de desconfiança e ceticismo grego para com o modelo de integração europeia, nomeadamente no que diz respeito à maior integração europeia nos domínios institucional, político e de defesa. A partir de 1985, porém, houve uma abertura maior a favor da cooperação europeia mais estreita, nos setores de saúde, educação e ambiente. A parte restante da década de 1980 viu a Grécia começar a sentir o benefício económico da sua adesão à CE e a experimentar os necessários processos de ajustamento (Tsoukalis 2020; Featherstone 2020).

Para muitos gregos, fazer parte da construção europeia tem sido uma escolha existencial devido à sua história e à sua geografia. Igualmente, existe um espírito de antiamericanismo no país relacionado com uma posição anti-imperialista de esquerda e uma perceção popular de condenação do apoio dos EUA à ditadura militar e a passividade nos trágicos desenvolvimentos na ilha de Chipre, em 1974. Memórias essas que refletem-se numa idiossincrasia política particular grega, contribuindo para a extensão da "Europeização"do país (o tema da "Europeização"da Grécia tem sido abordado por vários académicos ao longo dos anos: Lavdas 1997; Ioakimidis 2010; Tsardanidis e Stavridis 2011; Gemenis e Lefkofridi 2013; Featherstone e Papadimitriou 2020).

Com o fim da Guerra Fria, a Grécia encontrase de novo na fronteira da divisão e da instabilidade regional, marcada pela guerra da Jugoslávia. De facto, quando os regimes comunistas começaram a colapsar, a perspetiva de estabelecer relações amigáveis e mutuamente benéficas com os países vizinhos nos Balcãs foi o desafio seguinte para a Grécia. 


\section{O Século XXI: A identidade ao orá- culo de Apolo}

Uma versão nova da identidade grega, otimista e centrada na Europa, revela-se no início do século XXI. Identidade essa que encontrou a sua expressão mais marcante na cerimónia de abertura dos Jogos Olímpicos de Verão de 2004, em Atenas, onde as histórias antigas e modernas foram combinadas numa interpretação artística excecional.

A Grécia ambicionou e conseguiu o seu lugar na família europeia, fazendo parte do "núcleo duro"da construção europeia, como membro da zona euro. Tendo uma opinião pública favorável pró-europeísta, foi um dos países que mais apoiou o projeto para uma Constituição Europeia em 2004, e após a rejeição da mesma pela França e Holanda, advogou convictamente a inclusão das cláusulas integracionistas da Constituição no Tratado de Lisboa, que foi assinado em 2007.

Contudo, uma nova tragédia grega, não tardou a eclodir. A crise financeira de 2009 fez a Grécia enfrentar um dos momentos mais difíceis da sua história, ficando refém de um longo período de austeridade e exclusão. As medidas de austeridade tiveram um impacto gravíssimo na situação económica, política e social do país. A crise produziu uma mistura explosiva de xenofobia nacionalista, radicalismo de extrema-direita, inclusive a entrada no Parlamento Helénico do partido neonazi Aurora Dourada. Esta situação levou, por um lado, os dirigentes europeus a duvidarem do próprio "mérito"da Grécia de fazer parte do clube europeu; por outro lado, a falta de solidariedade e a imposição de regras insustentáveis por parte dos parceiros europeus levou a Grécia a duvidar do próprio projeto europeu e da sua sinceridade política e social. Assim, a Europa passou de um sinónimo de modernidade e crescimento económico para a causa principal da dolorosa austeridade vivida no país, relembrando o paternalismo eurocêntrico de um imperialismo ocidental do século XVIII (Triandafyllidou, Gropas e Kouki 2013, 17).

Por outro lado, a Grécia muitas vezes atuou como o "mau aluno"da Europa, dada a instabilidade económica do país, a falta de reformas estruturais e questões geoestratégicas complexas. De facto, a Grécia mantém uma base produtiva da economia fraca, maioritariamente com pequenas empresas de produção familiar. O consumo interno tem sido alimentado por défices orçamentais consideráveis. (Tsoukalis 2020). Além disso, também falharam os mecanismos de controlo, tanto interno como externo. O país passou por três programas de resgate sucessivos, com o último a terminar apenas em agosto de 2018. As políticas de austeridade impostas pelos credores não tiveram o efeito esperado. A crise aumentou as assimetrias económicas e sociais dentro da União, e a maioria dos Estados-Membros, e em particular os países mais fracos da zona euro, como a Grécia, não tiveram condições de promover o investimento e, consequentemente, o crescimento económico tão desejado e exigido pelos credores.

No mesmo período, a Grécia depara-se com um contexto geoestratégico instável: a relação de tensão constante com a vizinha Turquia, a disputa com a antiga "República Jugoslava da Macedónia"(FYROM), hoje Macedónia do Norte, sobre o nome deste país; situações essas que provocaram sentimentos de insegurança acrescida, dificilmente compreensível pelos parceiros europeus, pois para estes essas preocupações figuram como sendo pré-modernas ou irracionais. Porém, na verdade, a "insegurança muitas vezes gera irracionalidade"(Tsoukalis 2020, 589). Adicionalmente, a Primavera Árabe e a Guerra Civil na Síria em 2011 provocaram, além de instabilidade na região, o êxodo de centenas de milhares de migrantes e refugiados, prolongando e agravando as crises enfrentadas pelo Estado grego, uma das principais portas de entrada dos migrantes na União Europeia.

Neste contexto de múltiplas crises, o partido radical SYRIZA ganha as eleições em 2015, com uma posição muito crítica sobre a União Europeia. No entanto, o governo de Alexis Tsipras, apesar da sua campanha eleitoral contra o domínio de Bruxelas, e apesar do "não"a um novo plano de austeridade ter ganho no referendo de 5 de julho de 2015, acabou por manter o país bem perto das estruturas europeias. O crítico e eurocético ministro das Finanças na altura, Yannis Varoufakis, por outro lado, afasta-se do governo e cria o seu próprio partido, baseado numa retórica anticolonial europeia (Beaton 2019, 389). É pertinente, porém, notar que nunca defendeu explicitamente a saída da Grécia da União Europeia, mas uma 
visão diferente da Europa ${ }^{7}$. De facto, nos 40 anos de uma conturbada relação da Grécia com a União Europeia, sempre houve uma maioria próeuropeia, mesmo quando os gregos tinham uma opinião negativa sobre as políticas europeias ${ }^{8}$.

Durante o governo de Tsipras, a estreita ligação cultural, religiosa e histórica entre a Grécia e a Rússia veio de novo à superfície. Os dois países mantêm relações diplomáticas, militares e comerciais importantes, e uma ligação cultural e religiosa inegável. Porém, do ponto de vista político estratégico e institucional, a Grécia tem feito escolhas claras integrando-se ao mundo ocidental, e atuando em prol dos valores e princípios da União (Diamantouros 2013). Da parte da Rússia, o interesse centra-se no desafio do (des)equilíbrio nas relações de poder entre a Europa Ocidental e a própria, e a aproximação para com a Grécia encaixa-se neste molde.

Mark Mazower capta bem a tendência surpreendente da Grécia em superar as suas calamidades de modo revolucionário, prevalecendo mais vezes do que seria esperado, dado o seu peso demográfico, político e económico. Mazower baseia a sua afirmação em vários capítulos da história grega, entre eles: a Guerra da Independência Grega na década de 1820, que se tornou um símbolo de fuga do domínio dos impérios da época, e que se espalhou pelo continente, culminando na Primeira Guerra Mundial. A resistência aos nazis durante a Segunda Guerra Mundial, que estava entre os primeiros e mais visíveis esforços desse tipo. E, a democratização da Grécia em 1974, que antecipou uma onda de democratização global dos anos '80 e '90, primeiro na América do Sul e Sudeste Asiático e depois na Europa Oriental (Kalyvas 2015, 2020). A questão que se coloca agora é de saber se a crise grega e o "desacordo"para com o plano imposto pelos credores aos países em necessidade foram também o precursor de uma rutura sistémica do modelo capitalista do bem-estar neoliberal e de

7. Sobre o Manifesto for democratizing Europe e o European New Deal, ver a página oficial do DiEM25 https://diem25.org/ pt/ último acesso: 21 de março 2021

8. Eurobarómetro 4021 "Emotions and political engagement towards the EU", abril 2019, disponível em https://www.europarl.europa.eu/at-your-service/en/beheard/eurobarometer/emotions-and-political-engagementtowards-the-eu último acesso: 21 de março 2021 uma necessidade de mudança urgente (Triandafyllidou, Gropas e Kouki 2013, 8).

\section{Considerações Finais}

A Grécia celebra hoje 200 anos desde a sua independência, uma época marcada por períodos prolongados de instabilidade e guerra. Contudo, o país tem conseguido uma série de realizações significativas igualmente notáveis. Neste contexto, na identidade grega identifica-se um elemento de orgulho tanto pela sua história antiga como pelas suas realizações mais recentes. Todavia, também se identifica uma insegurança ligada à sua posição e relevância atual e ao seu lugar na Europa e no Mundo, entre o Ocidente e o Oriente.

Desde a génese do Estado Grego Moderno, a identidade grega foi marcada pelo conflito entre duas culturas distintas e antagónicas, a tradicionalista e a modernista. A cultura tradicional é nacionalista, influenciada pelo passado bizantino e otomano, marcada pela presença religiosa da Igreja Ortodoxa Cristã, e cética para com o modernismo europeu e pela presença pró-capitalista do mundo Ocidental. A cultura moderna, por outro lado, é cosmopolita e defende os valores e princípios liberais enraizados no modelo europeu desde o Iluminismo até hoje. O paradoxo, porém, da identidade grega é que elementos de ambas as culturas se encontram em todo o espectro da sociedade e sistema político, tanto nas forças de esquerda como de direita.

No entanto, colocar a Grécia definitivamente no Oriente, significaria desvalorizar a trajetória de um longo histórico de lutas e de um elo civilizacional e estratégico singular com o Ocidente. A Europa tem sido o espaço vital para a criação de uma identidade moderna para o novo Estado. Quanto às escolhas estratégicas e políticas, o caminho próocidental afigurou-se como a opção mais acertada para a Grécia. De igual modo, o valor da própria Grécia para com os seus parceiros europeus não pode ser ignorado. A ideia da Europa está intrinsecamente ligada à Grécia Clássica, desde o seu

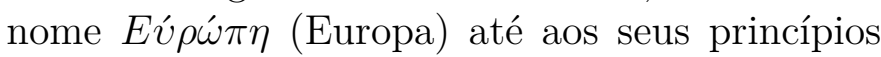
da filosofia, ciência e democracia. Desde a integração no projeto europeu, há 40 anos, a Grécia tem sido um pólo regional estratégico, um estado amigo e politicamente estável, e uma fronteira 
europeia que funciona como filtro das ameaças vindas dos países vizinhos, razão pela qual uma eventual saída da Grécia da zona euro ou da União Europeia (Grexit) não aparenta desejável.

Morin define a Europa como um complexo, cuja característica é reunir as maiores diversidades sem as confundir e de associar os contrários de maneira não separável (2010, 27). Esta associação define a nossa Europa e nela as identidades nacionais distintas encontram a sua melhor expressão.

Entre valores e visão estratégica, a psique ( $\psi v \chi \eta ́)$ clássica da Grécia está bem enraizada na Europa e vice-versa.

\section{Reconhecimento}

Este estudo foi elaborado no Centro de Investigação em Ciência Política (UID/CPO/00758/2020), Universidade de Évora, com o apoio da Fundação para a Ciência e Tecnologia (FCT) através de fundos nacionais.

\section{Referências}

[1] Arabatzis, Georgios, Steiris, Georgios e Mitralexis, Sotiris (eds). 2016. The Problem of Modern Greek Identity From the Ecumene to the Nation-State. Cambridge Scholars Publishing. 1st edition.

[2] Beaton, Roderick. 2019. Greece. Penguin Books Ltd. Edição do Kindle.

[3] Blinkhorn, Martin e Veremis, Thanos. (eds) Modern Greece: Nationalism and Nationality. Athens: ELIAMEP.

[4] Clogg, Richard. 1992. A Concise History of Greece University of Oxford. 1st edition.

[5] Daalder, Ivo H. 2000. "Europe: Rebalancing the U.S.European Relationship". Brookings. Disponível em https://www.brookings.edu/articles/europe-rebalancingthe-u-s-european-relationship/ último acesso: 11 de março 2021.

[6] Diamandouros, Nikiforos. 1983. "Greek political culture in transformation: historical origins, evolution, current trends". In Clogg, Richard (ed.) 1983. Greece in the 1980 s. London: Macmillan.

[7] Diamandouros, Nikiforos. 1993. "Politics and Culture in Greece, 1974-1991: An Interpretation". In R. Clogg (ed). Greece 1981-1989. The Populist Decade. New York: St Martins Press.

[8] Diamandouros, Nikiforos. 1994. "Cultural Dualism and Political Change in Postauthoritarian Greece" Working Paper 1994/50. Centro de Estudios Avanzados en Ciencias Sociales. Madrid.

[9] Diamandouros, Nikiforos. 2013. "Postscript: Cultural Dualism Revisited". In Triandafyllidou, Anna, Gropas, Ruby and Kouki, Hara. The Greek Crisis and European Modernity (Identities and Modernities in Europe). UK: Palgrave Macmillan. Edição do Kindle.

[10] Droulia, Loukia. 1997. "The Classics in the Service of Renascent Greece: Adamantios Korais and his Editorial Work". Humanitas. 49.

[11] Featherstone, Kevin e Papadimitriou, Dimitris. 2020. "The Politics of Europeanization". In Featherstone, Kevin e Sotiropoulos, Dimitri A. The Oxford Handbook of Modern Greek Politics. Oxford: Oxford Handbooks. Edição do Kindle.

[12] Featherstone, Kevin. 2020. "Introduction: Identifying Greece". In Featherstone, Kevin e Sotiropoulos, Dimitri A. The Oxford Handbook of Modern Greek Politics. Oxford: Oxford Handbooks. Edição do Kindle.

[13] Frary, Lucien. 2015. Russia and the Making of Modern Greek Identity, 1821-1844. Oxford: Oxford University Press

[14] Frary, Lucien. 2021. "The Orthodox Church". In Kitromilides, Paschalis M. e Tsoukalas, Constantinos (eds). The Greek Revolution: A Critical Dictionary. Belknap Press: An Imprint of Harvard University Press. Edição do Kindle.

[15] Gemenis, Kostas e Lefkofridi. Zoe. 2013. "Greece: A critical assessment of Europeanization". Disponível em file://C:/Users/evant/OneDrive/Downloads/GemenisLefkofridi_preprint\%20(1).pdf último acesso: 19 de março 2021.

[16] Hatzis, Aristides. 2019. "A political History of Modern Greece 18212018"In: Marciano, Alain, Ramello, Giovanni Battista (eds.). Encyclopedia of Law and Economics. New York: Springer. https://doi.org/10.1007/978-1-4614-77532_53 último acesso: 25 de março 2021.

[17] Hatzivassiliou, Evanthis. 2006. Greece and the Cold War: Front Line State, 1952-196\%. London: Routledge.

[18] Hatzivassiliou, Evanthis. 2020. "Constantine Karamanlis". In Featherstone, Kevin e Sotiropoulos, Dimitri A. The $O x$ ford Handbook of Modern Greek Politics. Oxford: Oxford Handbooks. Edição do Kindle. 
[19] Holland, Robert. 2021. "Navarino". In Kitromilides, Paschalis M. e Tsoukalas, Constantinos (eds). The Greek Revolution: A Critical Dictionary. Belknap Press: An Imprint of Harvard University Press. Edição do Kindle.

[20] Ioakimidis, Panagiotis. 2010. The Lisbon Treaty. Athens: Themelio. In Greek. 2nd edition.

[21] Kalyvas, Stathis. 2015. Modern Greece (What Everyone Needs To Know). Oxford University Press. Edição do Kindle.

[22] Kalyvas, Stathis. 2020. "The Developmental Trajectory of the Greek State". In Featherstone, Kevin e Sotiropoulos, Dimitri A. The Oxford Handbook of Modern Greek Politics. Oxford: Oxford Handbooks. Edição do Kindle.

[23] Karamouzi, Eirini. 2014. Greece, the EEC and the Cold War, 1974-1979. The Second Enlargement. London: Palgrave Macmillan.

[24] Kitromilides, Paschalis M. 2013. Enlightenment and Revolution: The Making of Modern Greece. Cambridge, MA and London: Harvard University Press.

[25] Kitromilides, Paschalis M. 2020. "Church, State, and Hellenism". In Featherstone, Kevin e Sotiropoulos, Dimitri A. The Oxford Handbook of Modern Greek Politics. Oxford: Oxford Handbooks. Edição do Kindle.

[26] Kitromilides, Paschalis M. 2021. "Enlightenment". In Kitromilides, Paschalis M. e Tsoukalas, Constantinos (eds). The Greek Revolution: A Critical Dictionary. Belknap Press: An Imprint of Harvard University Press. Edição do Kindle.

[27] Koliopoulos John e Veremis, Thanos. 2010. Modern Greece, a History since 1821. Oxford: Wiley-Blackwell Editions. 2010. 1st edition.

[28] Lavdas, Kostas A. 1997. The Europeanization of Greece. Interest Politics and Crises of Integration. London: Palgrave Macmillan.

[29] Lazaridis, I., Mittnik, A., Patterson, N. et al. 2017. "Genetic origins of the Minoans and Mycenaeans". Nature. 548: 214-218. https://doi.org/10.1038/nature23310 último acesso: 11 de março 2021.

[30] Mitralexis, Sotiris. 2017. "Modern Greece Between East and West: Hysteria and Otherness". IN $\Sigma \Pi O \Lambda$ -

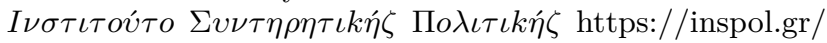
2017/07/02/hysteria_and_otherness/ último acesso: 21 de março 2021.

[31] Morin, Edgar. 2010. Pensar a Europa. S.I.: Publicações Europa-América.

[32] Skopetea, Elli. 1988. To Protypo vasileio kai $i$ megali idea (1830-1880). Athens: Politypo.

[33] Stamatoyannopoulos, G., Bose, A., Teodosiadis, A. et al. 2017. Genetics of the peloponnesean populations and the theory of extinction of the medieval peloponnesean Greeks. European journal of human genetics. 25, 637-645. https:// www.nature.com/articles/ejhg201718 último acesso: 05 de março 2021.

[34] Triandafyllidou, Anna, Gropas, Ruby and Kouki, Hara. 2013. Introduction: Is Greece a Modern European Country? In Triandafyllidou, Anna, Gropas, Ruby and Kouki, Hara. The Greek Crisis and European Modernity (Identities and Modernities in Europe), UK: Palgrave Macmillan. Edição do Kindle.

[35] Tsardanidis, Charalambos e Stavridis Stelios. 2011. "Greece: from special case to limited Europeanization". In Wong, E Reuben, Hill Christopher. National and European Foreign Policies. Towards Europeanization. 1st edition, https://www.taylorfrancis.com/books/ edit/10.4324/9780203816035/national-european-foreign- policies-reuben-wong-christopher-hill último acesso: 25 de março 2021.

[36] Tsoukalas, Constantinos. 1999. "European modernity and Greek national identity". Journal of Southern Europe and the Balkans. 1(1), 7-14, https://www.tandfonline.com/ doi/abs/10.1080/14613199908413983 último acesso: 25 de março 2021.

[37] Tsoukalas, Constantinos. 2002. "The irony of symbolic reciprocities: the Greek meaning of Europe as a historical inversion of the European meaning of 'Greece'". In Malmborg, M. and Strath, B. (eds). The Meaning of Europe. Oxford: Berg.

[38] Tsoukalas, Constantinos. 2021. "Symbolic Commemorations and Cultural Affiliations". In Kitromilides, Paschalis M. e Tsoukalas, Constantinos (eds). The Greek Revolution: A Critical Dictionary. Belknap Press: An Imprint of Harvard University Press. Edição do Kindle.

[39] Tsoukalis, Loukas. 1981. The European Community and Its Mediterranean Enlargement. London: George Allen \& Unwin.

[40] Tsoukalis, Loukas. 2020. "Greece and the European Union strategic vision, diplomatic finesse and poor domestic delivery". In Kevin Featherstone and Dimitris Papadimitriou. The Oxford Handbook of Modern Greek Politics, Oxford: Oxford Handbooks. Edição do Kindle.

[41] Tzogopoulos, George. 2013. The Greek Crisis in the Media: Stereotyping in the International Press. NY: Routledge. 1st edition.

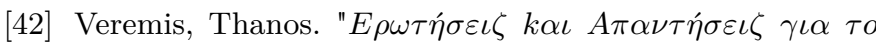

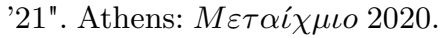

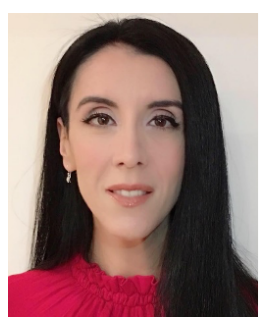

Evanthia Balla is an Assistant Professor at the University of Évora and Collaborative member of the Research Center in Political Science (CICP). Evanthia Balla has a PhD in Political Science and International Relations from the Catholic University of Lisbon (Portugal), a Masters degree in European Studies from the University of Reading (UK) and a Masters degree in International Politics from the Université Libre de Bruxelles (Belgium). 